\title{
Alveolar Reconstruction using Osteointegrated Mini-implant for Distraction Osteogenesis: A Clinical Report
}

\section{Túlio Del Conte Valcanaia, Gisele Luz Bustamante, Ricardo Quírico Pinheiro Machado}

\begin{abstract}
Oral rehabilitation with dental implants, from the simplest to the most complex, has become a frequent procedure in dental offices. Currently, clinical excellence involves placing implants in diameter and size appropriate. In order to achieve this goal, it is often necessary to reconstruct the alveolar process of the patient. One of the techniques used for this purpose today is distraction osteogenesis, which has proven to be an effective and predictable technique. The objective of this article is to present a clinical case of partial reconstruction of the alveolar bone, using mini-implants to anchor the bone block that will be moved. This variation of the conventional technique minimizes the risks inherent in using conventional distractors.
\end{abstract}

Keywords: Implants, Mini-implants, Distraction osteogenesis.

How to cite this article: Valcanaia TDC, Bustamante GL, Machado RQP. Alveolar Reconstruction using Osteointegrated Mini-implant for Distraction Osteogenesis: A Clinical Report. Int J Oral Implantol Clin Res 2012;3(3):146-149.

Source of support: Nil

Conflict of interest: None declared

\section{INTRODUCTION}

The osteointegrated implants offer the possibility of prosthetic rehabilitation of the stomatognathic system, allowing the re-establishment of the adequate esthetics and phonetically function, beyond returning to the patient its self-esteem.

When you think about rehabilitation with oral implants, an important aspect to be considered is that the distribution of masticatory loads and the final esthetic result of the possibility of placing implants in number, size and position ideals. ${ }^{4}$ Many times the patient has no alveolar bone in sufficient quantity so that these conditions are met.

In these cases, the distraction osteogenesis is a surgical technique that can restore bone volume necessary to obtain the desired success.

The osteogenic distraction is a form of in vivo tissue engineering, in which the gradual separation of the bone edges, surgically cut, results in a new bone. ${ }^{1,11}$

The tissue regeneration produced by the osteogenic distraction was widely used in the orthopedics to regenerate long bones after the shortening of an inferior member for trauma, osteomyelitis or another condition. A limited success was noticed in the formation of new bone tissue and, in special, the union of the bones fragments distracted.
This type of procedure can cause a high incidence of complications and, as consequence, the majority of the orthopedic professionals used to focus their attention in the shortening of the members in normal dimensions or in the use of external prosthesis to compensate the differences of length of members.

The idea of the elongation of the human body bones was initiated in 1905 by Codvilla, for orthopedic purposes. Other authors had followed this technique, but only later, in the decade of 40, a Russian orthopedist, named Ilizarov, realized a systematic study, with biological base and clinical reliability, promoting de bone elongation by osteogenic distraction and getting consistent results. These studies preceded the development of a great variety of applications to the dental facial area, varying between advances of the midface procedures to the dental movement.

According to many authors, ${ }^{7}$ the osteogenic distraction is pointed currently, as the only strategy capable simultaneously to correct defects of bones and soft parts, conferring the pre-existing dimensions and biomechanics properties to them.

Currently, the procedure has been used in the treatment of vertical resorption of edentulous areas, to allow the installation of osteointegrated implants, with predictable results. ${ }^{5,6}$

This study reports a development of the conventional alveolar distraction osteogenesis, where traditional anchoring apparatus of the bone block are replaced by mini dental implants, in order to simplify the surgical technique and minimize the morbidity inherent in this technique. ${ }^{12}$

\section{CLINICAL REPORT}

A female patient was referred for treatment to recuperation of alveolar bone loss in the lower jaw, left side.

The patient was presented with one implant fractured and a second was removed because there was loss in its osseointegration, 5 years after its placement (Figs 1 and 2).

The alveolar distraction technique, using the osteointegrated mini-implant, was suggested to the patient, who accepted the procedure.

The patient was submitted to the placing of the miniimplant in the medium position of the block and preserved for 4 months up to the osteointegration be confirmed.

After this period, the distraction surgery was performed, initiated with an incision on the alveolar ridge, detachment 


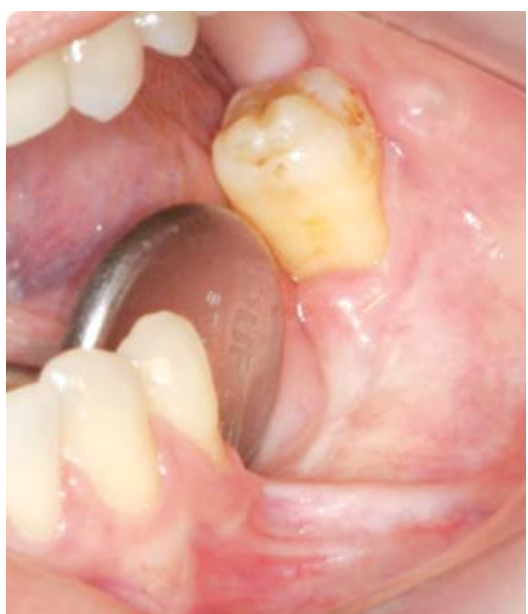

Fig. 1: Initial photo showing the alveolar bone loss

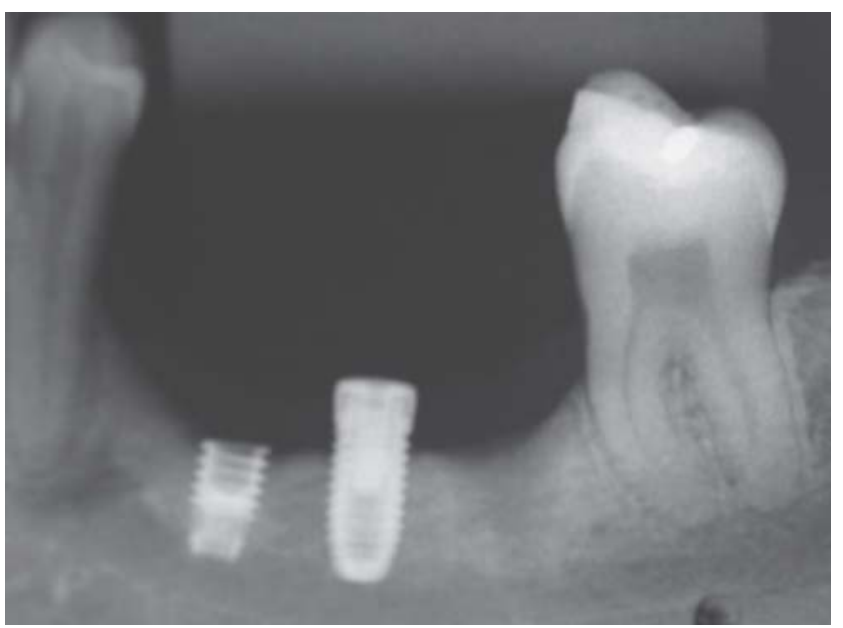

Fig. 2: X-ray showing alveolar bone loss, fractured implant, mini-implants installed and socket of the implant removed due to loss of osseointegration

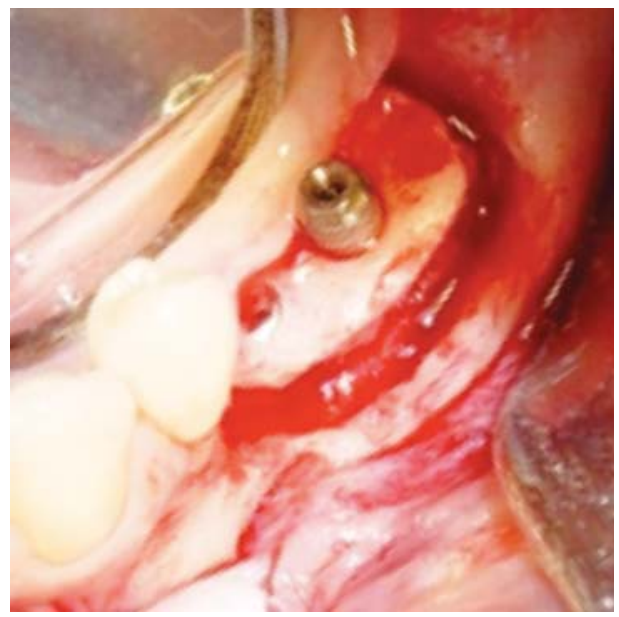

Fig. 3: Osteotomy of the vestibular cortical bone block enclosing the bone block to be moved

and diversion of the flap, with exposition of the mental nerve. With a number H254 bur/drill $\left(\right.$ Komet $^{\circledR}$ ) of high speed, the osteotomy was done, interesting the vestibular cortical of the bone block. Following, with a delicate chisel, the osteotomy was finalized, fracturing the medullar and

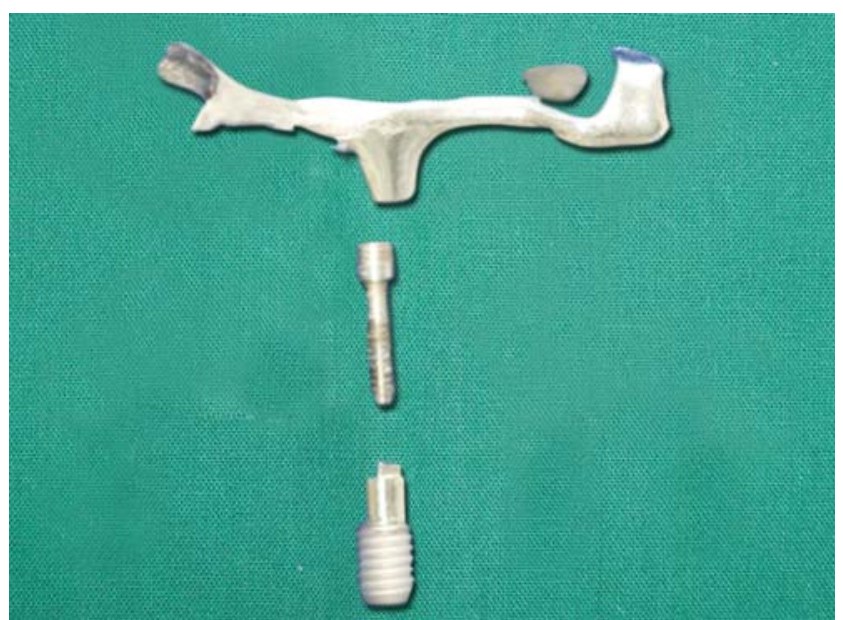

Fig. 4: Metallic bar, lag screw and mini-implant

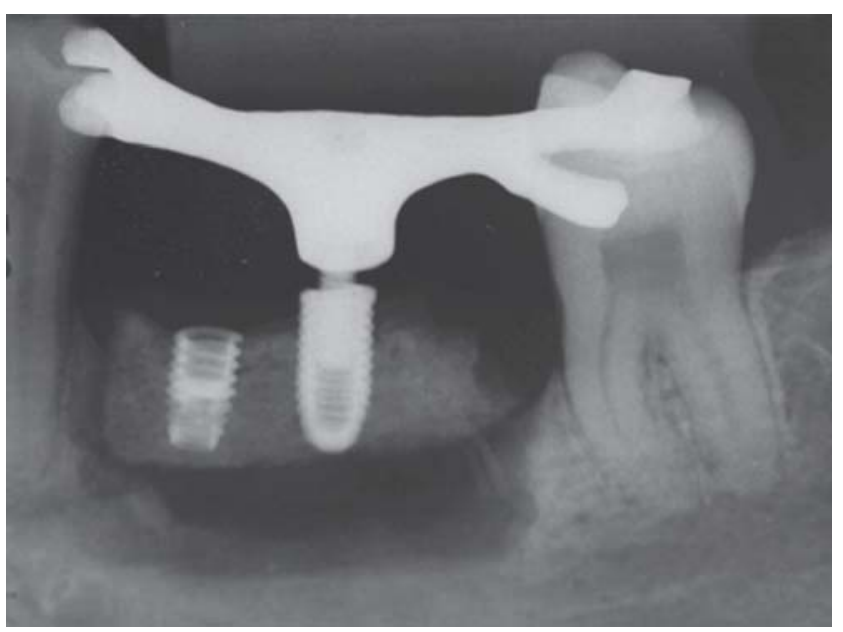

Fig. 5: Periapical radiograph showing the bone block being pulled

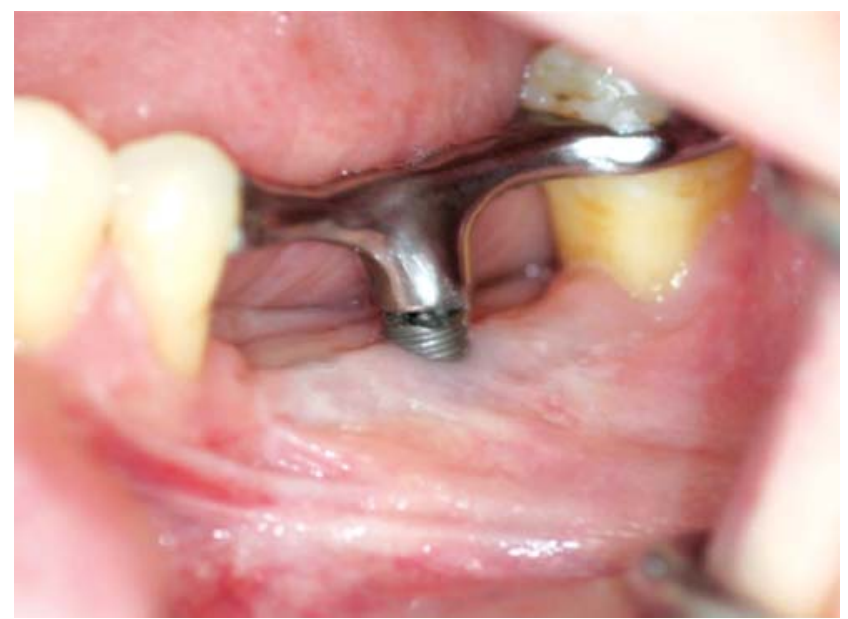

Fig. 6: Bar metal screw and mini-implants stabilized after the final elevation of the block

the lingual cortical, causing no injury to the mandible vascular nervous bundle and to the periosteum of the lingual region (Fig. 3).

Using the mini-implant as support, the fracturing of the block was completed. After verifying the mobility of the 


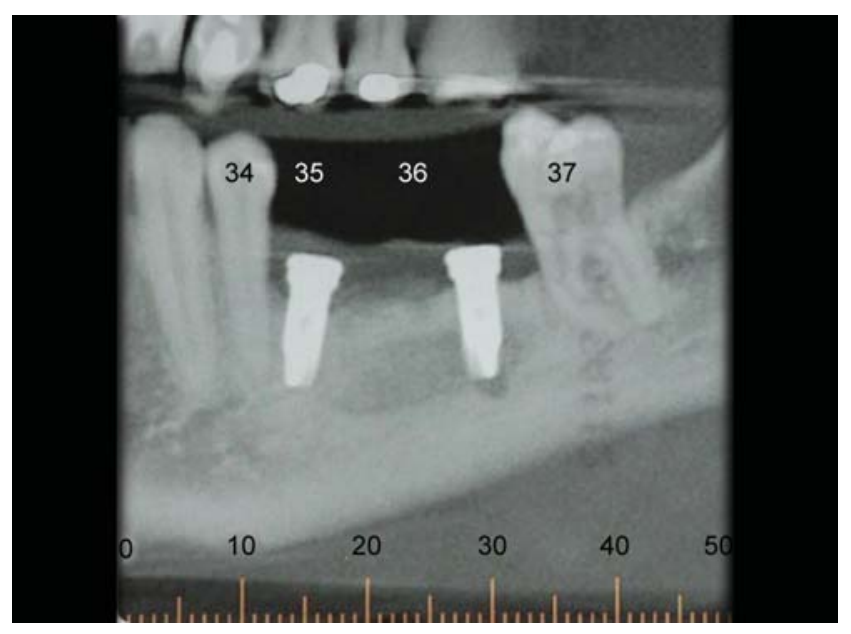

Fig. 7: Radiograph showing implants placed

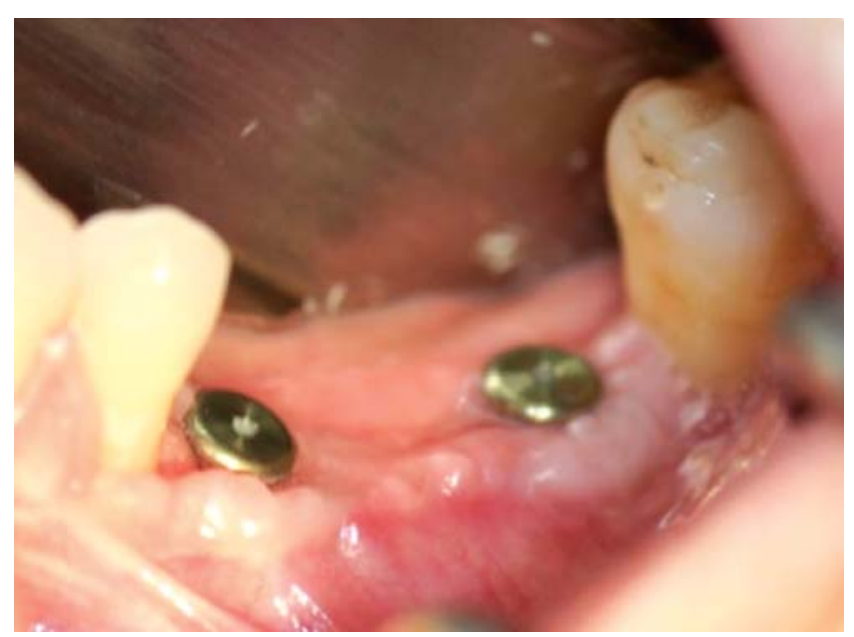

Fig. 8: Clinical view of two osseointegrated implants

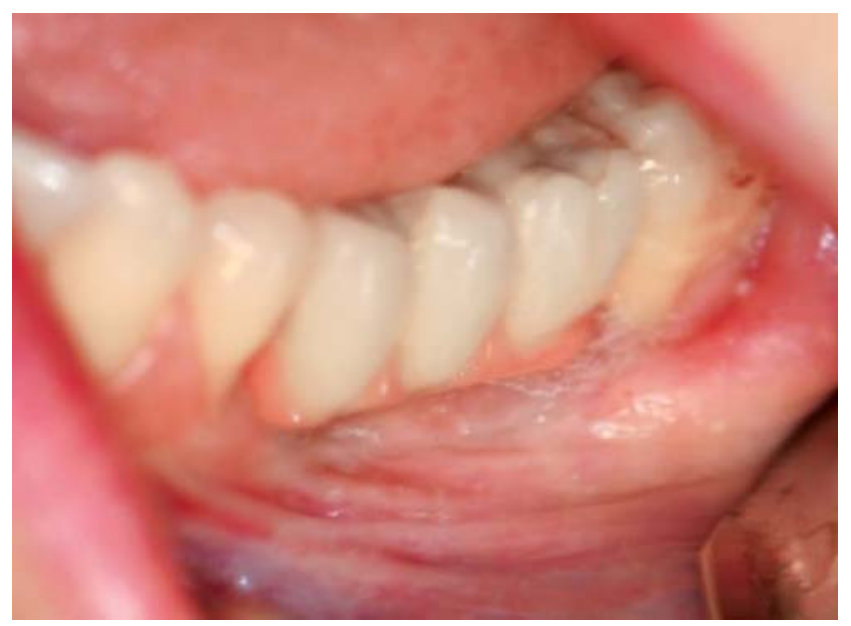

Fig. 9: Clinical view of the prosthetic resolution

bone block, a suture was performed and a metallic bar was installed (Fig. 4) and supported on teeth 34 and 37.

The bar was prepared with a perforation in the region of mini-implant to allow insertion and anchoring of a lag screw, which has the function to slowly pull the mini-implant, as it is screwed inside this. As the bar was established, the traction screw was introduced until the entrance of the external orifice of the mini-implant, which, with the bone block was positioned in order to allow small introduction of the screw in the internal thread of the mini-implant (Fig. 5).

The patient returned after 7 days to remove the suture and to proceed to the activation of the screw. The activation was of $0.7 \mathrm{~mm}$ a day, until the mini-implant reached the bar. The tractioning and direction screw was stucked with methyl methacrylate after the end of the traction (Fig. 6).

After 90 days, the patient was submitting to a computerized tomography and she was ready for the removal of the capsule and the fractured implant and so, the placement of the implants (Fig. 7).

Final result of the remodeling of bone and gingival architecture (Fig. 8).

Prosthetics rehabilitation is shown in Figure 9.

\section{DISCUSSION}

The osteogenic distraction is a method of lengthening the bone tissue by the modulation of the osseous clavi. The process involves an osteotomy, followed by the controlled and continuous gradual distraction (separation) of the osseous segments, creating a tension in the bone callus that stimulates the local histogenesis. ${ }^{2}$ The tension activates the cellular metabolism, increasing the protein synthesis and the mitotic index, being possible the formation of hard and soft tissues, adjacent to the space produced by distraction. ${ }^{7}$

The preservation of the sanguine supply of the region to be distracted is the first factor for the accomplishment of the osteogenic distraction. The tissue regeneration produced by this technique depends on the maintenance of an adjusted vascularization of the area when the distraction of the osseous fragments is done. ${ }^{3,8}$ Many surgical techniques for the osseous section had been developed, ${ }^{10}$ and all aim at to preserve the sanguine supply of the periosteum, endosteum and bone marrow to optimize the induction of the regeneration. The main techniques are: (1) Osteotomy that completely separates the two fragments to be distracted, including the sponges bone; (2) the corticotomy that preserves the integrity of the marrow spaces and sponges bone; (3) the osteotomy that extends over part of the sponges bone followed by the induction of an orientated fracture in the remaining portion.

Additionally, if an adjusted care is taken with the manipulation of soft tissues, the sanguine aspect of the distracted area, will be resembled to a trauma fracture, where the repair is favored by the preservation of adjacent soft tissue. ${ }^{8,9}$ 
To initially activate the distraction device, an interval of 7 days was used. This period of latency still presents controversies in literature. According same authors ${ }^{13}$ this period goes to 5 to 7 days, other authors suggest 7 days, and others investigators defend 14 days. ${ }^{14}$

The rate of activation, ${ }^{3}$ is the resultant of the daily movement of the block. Literature indicates variation of 0.5 to $1.0 \mathrm{~mm}$, depending on the technique, until getting the intended length. In movement of bigger blocks, the rate of $1.0 \mathrm{~mm}$ is considered ideal for the formation of the bone tissue, therefore in the rate of $0.5 \mathrm{~mm}$ ossification can occur prematurely.

In the presented case, as being a small block and with a little amplitude displacement was opted to a movement of $0.7 \mathrm{~mm}$. This rate has been revealed as ideal for distraction of alveolar blocks.

The period of consolidation occurs after the activation of the device is finished. ${ }^{13}$ It is the necessary period for the ossification of the area gotten between the block and the remaining ridge. After the repair of this area is done, the distractor capsules and the prosthetic device of containment can be removed. The minimum period that is used is of 3 months.

Some authors ${ }^{3}$ suggest that factors such as age and final length of the distraction must be evaluated and those radiographic and tomographic examinations can be used for the study of the focus of distraction and to assist in the determination of the ideal time for removing the distractor. Many authors ${ }^{15}$ defend a time of consolidation of 10 weeks, while others, ${ }^{16}$ report an average time of 6 to 8 weeks.

\section{CONCLUSION}

The technique of the osteointegrated device for distraction osteogenesis is a procedure that simplifies the adaptation of the distractor device to bone tissue, minimizing postoperative complications.

It allows the use of the prosthesis during the entire treatment, avoiding esthetic problems or even the social life is impaired.

It allows the rehabilitation of large defects in small areas or large extensions of the alveolar ridge.

\section{REFERENCES}

1. Robiony M, Toro C, Stucki-McCormick SU, Zerman N, Costa F, Politi M. The 'FAD' (Floating Alveolar Device): A bidirectional distraction system for distraction osteogenesis of the alveolar process. J Oral Maxillofacial Surg 2004;62: 136-42.

2. De Bastiani G, et al. Limb lengthening by callus distraction (callotasis). J Pediatr Orthop 1987 Mar/Apr;7(2):129-34.
3. Ilizarov GA. The tensión-stress on the genesis and growth of tissues: Part 2. The influence of the rate and frequency of the distraction. Clin Orthop 1989 Feb;239:263-85.

4. Little RM. Stability and relapse of dental arch alignment. Br J Orthod, 1990 Aug;17(3):235-41.

5. Block MS, Baughman DG. Reconstruction of severe anterior maxillary defects using distraction osteogenesis, bone grafts, and implants. J Oral Maxillofac Surg 2005 Mar;63(3):291-97.

6. Pereira-Filho VA, Vieira EH. Gabrielli MAC Queiroz TP, Chávez OFM. Distração osteogênica mandibular para instalação de implantes: relato de caso. Rev. Cir Traumatol Buco-Maxilofac, Camaragibe 2007 Jan/Mar;7(1):51-58.

7. Dinato JC, Polido WD. Implantes osseointegrados: cirurgia e prótese. São Paulo: Artes Médicas 2001;398.

8. Aronson J. Temporal and spatial increases in blood flow during distraction osteogenesis. Clin Orthop 1994 Apr;301:124-31.

9. Faber J, Azevedo RB, Báo SN. Aplicações da distração osteogênica na região dentofacial: o estado da arte. R Dental Press Ortodon Ortop Facial, Maringá 2005 Jul/Ago;10(4): 25-33.

10. Uckan S, Haydar SG, Imirzalioglu P, Acar AG. Repositioning of malpositioned segment during alveolar distraction. J Oral Maxillofacial Surg 2002;60:963-65.

11. Iizuka T, Hallermann W, Seto I, Smolka W, Smolka K, Bosshardt DD. Bi-directional distraction osteogenesis of the alveolar bone using an extraosseous device. Clin Oral Impl Res 2005;16:700-07.

12. Valcanaia TD, Palma FR, Chaves, AC Jr. Reposicionamento de implantes osseointegrados com a utilização de dispossitivos protéticos para distração óssea alveolar BCI. Curitiba 2001 Oct/Dec;8(32):302-05.

13. Ilizarov GA. Clinical application of the tension-stress effect for limb lengthening. Clin Orthop 1990 Jan;250:8-26.

14. Maccarthy JG, et al. Lengthening the human mandible by gradual distraction. Plast Reconstr Surg 1992 Jan;89(1):1-10.

15. Block MS, et al. Bone response to functioning implants in dog mandibular alveolar ridges augmented with distraction osteogenesis. Int J Oral Maxillofac Implants 1998 May/June; 13(3):342-51.

16. Soares $\mathrm{M}$, Bauer J. Increase of the mandibular alveolar ridge with internal distraction osteogenesis device. Int J Oral Maxillofac Surg 1999;28(Suppl 1):143.

\section{ABOUT THE AUTHORS}

\section{Túlio Del Conte Valcanaia}

Professor, Department of Oral and Maxillofacial Surgery, Itajai University, Brazil; Professor of Implantology, Dentistry Institution of Americas, Brazil

Correspondence Address: Cônego Thomas Fontes Street, No. 480 Office 21, 22-Bamerindos Building, Itajai, SC, Brazil, Zip: 88300060-Downtown, e-mail: ipgv@hotmail.com

\section{Gisele Luz Bustamante}

Professor, Department of Implantology, Dentistry Institution of Americas, Brazil

\section{Ricardo Quírico Pinheiro Machado}

Professor, Department of Implantology, Dentistry Institution of Americas, Brazil 